\title{
Jerneja PASIVNI NEDOLOČNIŠKI KAVČIČ POLSTAVKI, ODVISNI OD GLAGOLOV UKAZOVANJA: POGLED S STALIŠČA TEORIJE NARAVNOSTI
}

\section{Izvleček}

Pričujoči prispevek obravnava eno od značilnosti skladnje nedoločniških polstavkov v klasični in poklasični grščini, to je rabo pasivnih nedoločniških polstavkov $\mathrm{v}$ primeru izpuščenega naslovnika za glagoli ukazovanja (stavki tega tipa so bolj znani iz latinščine, prim. Caesar pontem fieri iussit). Namen prispevka je predstaviti tudi osnovna izhodišča teorije naravnosti in prikazati, kaj lahko teorija naravnosti pove o navedenem tipu nedoločniških polstavkov.

\begin{abstract}
The aim of the paper is, firstly, to outline the Naturalness Theory (NT) as it has developed in its latest version at the University of Ljubljana. Secondly, it investigates the use of passive infinitive clauses dependent on the verbs of ordering (a phenomenon more commonly known from the Latin clause type Caesar pontem fieri iussit) and interprets them in terms of the NT.
\end{abstract}

\section{Kratka predstavitev teorije naravnosti}

Teorija naravnosti se je od osemdesetih let 20. stoletja razvijala zlasti na nekaterih avstrijskih in nemških univerzah, pa tudi na Filozofski fakulteti v Ljubljani pod vodstvom profesorja Janeza Orešnika. Prvotno se je razvijala na področju glasoslovja in oblikoslovja, kasneje tudi na področju skladnje. Na področju skladnje je teorijo naravnosti razvijala in jo še vedno razvija zlasti t.i. slovenska šola naravne skladnje.

Osnovni pojmi teorije naravnosti:

\section{I. sem in sym naravnost}

Po teoriji naravnosti obstajata v jeziku dve vrsti naravnosti, 'sem naravnost' in 'sym naravnost'. Sem naravno je tisto, kar je bolj naravno $s$ stališča govorca, po teoriji naravnosti pa je interes govorca $v$ tem, da bi se izražal kar najbolj preprosto in varčno. Sym naravnost pomeni naravnost $\mathrm{s}$ stališča poslušalca, in po teoriji naravnosti je interes poslušalca $\mathrm{v}$ tem, da bi prejel kar najbolj jasno ali transparentno sporočilo. Po teoriji naravnosti si 'sym' in 'sem naravnost' nasprotujeta. Kar je bolj 'sem naravno', je hkrati manj 'sym naravno', zato je vsako lestvico naravnosti možno obrniti: $>\operatorname{sem}(\mathrm{A}, \mathrm{B}) \rightarrow<\operatorname{sym}(\mathrm{A}, \mathrm{B})$

Za bolj sem naravno kategorijo (v tem primeru A) se je zlasti na 
začetku uporabljal izraz šibka dvojnica, za manj sem naravno dvojnico (B) pa izraz krepka dvojnica.

Znotraj slovenske šole teorije naravnosti se uporabljata dve razširjeni lestvici naravnosti, po katerih je neobvezna raba manj naravne kategorije bolj ugodna za govorca kot (ali bolj sem naravna) kot obvezna raba manj naravne kategorije. Lestvica tega tipa se izrazi kot $>$ sem $(A+B, B)$.

Po drugi razširjeni lestvici je obvezna raba bolj naravne kategorije bolj ugodna za govorca (ali bolj sym naravna) kot neobvezna raba manj naravne kategorije. Lestvica tega tipa se izrazi kot $>\operatorname{sem}(A, A+B)$.

Vsaka razširjena lestvica velja za utemeljeno, če je utemeljena osnovna lestvica (>sem $(\mathrm{A}+\mathrm{B}))$.

Namesto izraza 'sem naravnost' se uporablja tudi izraz 'naravnost', zato se namesto znamenja '>sem' uporablja tudi znamenje '>nat'. ${ }^{1}$ Izraz 'naravnost' ustreza tudi izrazu '(ne) zaznamovanost', prim. Orešnik (2001), 223. Kar je bolj naravno ali bolj sem naravno, je manj zaznamovano.

\section{II. skladenjske dvojnice}

Teorija naravnosti obravnava na področju skladnje pojave, ki jih imenuje dvojnice. Na začetku je veljalo, da skladenjski dvojnici predstavljata dve (približno) sinonimni skladenjski tvorbi, prim. Orešnik (1999), 10. V grški slovnici bi tak primer predstavljali nedoločniški polstavki in predmetnik odvisniki, uvedeni $z$ veznikom ő $\iota$, ker se oboji, kot je znano, lahko uporabljajo kot dopolnilo glagolov govorjenja in mišljenja brez bistvene pomenske razlike; ta dvojnica je natančneje obravnavana spodaj. Kasneje se izkazalo, da je pojem dvojnici možno razumeti tudi v nekoliko širšem pomenu, prim. Orešnik (2001).

Teorija naravnosti na področju skladnje napoveduje, da se bolj sem naravna (šibka) dvojnica uporablja v bolj sem naravnih (preprostih) okoliščinah od manj sem naravne (krepke) dvojnice (t. j. povezuje se $z$ vsaj enim bolj naravnim parametrom kot manj sem naravna (krepka) dvojnica). Vendar se ne napoveduje, v kakšnem smislu se te okoliščine preproste, temveč samo to, da se bolj sem naravna dvojnica $v$ nekem pogledu (vsaj enem) povezuje z bolj naravnimi okoliščinami.

Ta napoved se s pomočjo lestvic naravnosti izrazi:

$>$ sem se povezuje $s>$ sem

Če se upošteva, da poleg sem naravnosti obstaja sym naravnost, in da je si obe vrsti naravnosti nasprotujeta, je isto napoved možno izraziti tudi kot: $>$ sem se povezuje $\mathrm{s}<$ sym

ali

$>$ sym se povezuje $\mathrm{s}<$ sem $^{2}$

1 Prim. Mayerthaler I, II, Orešnik (2003).

2 Za vse različice napovedi prim. Orešnik (2001),12. 
Ker je vsako lestvico >sem naravnosti v slovenski šoli naravne skladnje možno spremeniti v lestvico >sym naravnosti in obratno, je najbolj v rabi prva od navedenih lestvic naravnosti (>sem se povezuje $s>$ sem), ki jo je možno izraziti tudi kot $>$ nat se povezuje $\mathrm{z}>$ nat.

\section{Merila za določanje sem naravnosti}

Za določanje sem naravnosti se $\mathrm{v}$ slovenski šoli naravne skladnje uporablja 10 načel, ki so eden glavnih prispevkov slovenske šole naravne skladnje k teoriji naravnosti. Gre za naslednjih 10 načel:

\section{1. načelo manjšega napora}

To je osnovno načelo pri določanju sem naravnosti. Tisto, kar zahteva manj napora, je ugodneje za govorca, zato je bolj sem naravno. Tako so nikalni stavki po načelu manjšega napora manj naravni od trdilnih stavkov, ker je za tvorbo nikalnih stavkov potrebna ena beseda več (to je nikalnica). Načelo se lahko uporabi tudi pri določanju naravnosti nedoločniških polstavkov, o čemer prim. sp.

\section{2. filogenetsko načelo}

To načelo se za razliko od ostalih načel, ki izhajajo iz sinhronega opisa jezika, nanaša na diahroni vidik. Kar je bolj sem naravno se ponavadi v zgodovini jezika pojavi prej od manj sem naravnega (npr. glavni in odvisni stavki). Načeloma se tudi pričakuje, da v procesu izginjanja manj sem naravna dvojnica izgine prej kot bolj sem naravna dvojnica.

To načelo, ki je bilo v rabi do nedavnega, se v zadnjem času opušča, za kar obstajata najmanj dva razloga. Kljub temu, da se ne trdi, da povezava med sinhronim in diahronim vidikom ne obstaja, se je izkazalo, da je raba filogenetskega načela $v$ veliki meri nepotrebna, ker je lestvice naravnosti skoraj vedno možno utemeljiti s pomočjo katerega drugega od desetih načel za določanje sem naravnosti. Še pomembnejši razlog, zaradi katerega se filogenetsko načelo opušča, pa je ta, da se je pojavilo nekaj primerov, kjer filogenetsko načelo nasprotuje drugim načelom za določanje sem naravnosti.

\section{3. načelo prototipičnosti}

Kar je bolj prototipično, je bolj sem naravno. Tako je samostalnik bolj prototipična samostalniška beseda od posamostaljenega pridevnika, zato je bolj sem naraven od posamostaljenega pridevnika. 


\section{4. načelo včlenjenosti v stavek}

Kar je bolj včlenjeno v stavek, je bolj sem naravno. Tako je tožilniški predmet bolj včlenjen $\mathrm{v}$ stavek od prislovnega določila, ker se tožilniški predmet ujema v spolu, sklonu in številu s svojo odnosnico, zato je tožilniški predmet bolj naraven stavčni člen od prislovnega določila. Na splošno so argumenti bolj naravni stavčni členi od neargumentov. To načelo se lahko uporabi tudi pri določanju naravnosti nedoločniških polstavkov, o čemer prim. sp.

\section{5. pogostnost}

Kar je v jeziku pogostejše, je bolj sem naravno, na primer glagol biti v primerjavi z drugimi glagoli. Vendar ne velja, da je vse, kar je zelo sem naravno, tudi zelo pogosto. $V$ najnovejši različici teorije naravnosti načelo pogostnosti velja samo za pojavnice in ne tudi za različice, prim. Orešnik (2004), 14.

\section{6. načelo manjšega razreda}

Majhen razred (množica, katere enote je možno prešteti) je bolj naraven od velikega razreda; $v$ grščini bi bilo kot primer manjšega razreda

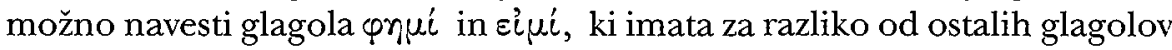
nekatere oblike enklitične.

\section{7. specializirana proti nespecializlirani rabi}

Specializirana raba neke kategorije je bolj naravna od nespecializirane rabe. Enega od primerov predstavljajo slovnična števila ednina, dvojina in množina. S tipološkega vidika gotovo drži, da je dvojina najmanj naravno število, ker je marsikateri jezik nima. Vendar pa s stališča načela 7 za določanje naravnosti velja tudi, da je v jeziku, ki loči med ednino, dvojino in množino, dvojina (in ne množina) najbolj naravna slovnično število za izražanje dvojnosti.

\section{8. tipološko načelo}

Kar je bolj razširjeno po jezikih sveta, je bolj sem naravno, prim. zg. o slovničnih številih in spodaj o naravnosti nedoločniških polstavkov.

\section{9. raba proti nerabi nekega postopka oz. raba proti nerabi neke} kategorije

Raba neke kategorije ali postopka je bolj sem naravna kot neraba kategorije ali postopka.

\section{0. načelo sprejemljivosti}

Kar je bolj sprejemljivo za govorca, je bolj sem naravno. 


\section{Določanje sym naravnosti}

Glavno načelo pri določanju sym naravnosti je načelo transparentnosti. Kar je bolj transparentno, je bolj sym naravno, ker je ugodneje s stališča poslušalca. $V$ grščini enega od takšnih primerov predstavlja raba podvojene nikalnice, $v$ stavkih tipa oú $\mu \dot{\eta} \pi \alpha u ́ \sigma \omega \mu \alpha \iota \quad \varphi \iota \lambda \circ \sigma o \varphi \tilde{\omega} v$; na ta način je poslušalec dvakrat obveščen o vsebini sporočila, medtem ko je v stavku tipa oủ $\pi \alpha u ́ \sigma o \mu \alpha \iota ~ \varphi \iota \lambda o \sigma o \varphi \tilde{\omega} v$ o tem, da je stavek zanikan, obveščen le enkrat. Kot rečeno, je vsako lestvico naravnosti, ki je utemeljena po enem izmed načel za določanje sem naravnosti (=s stališča govorca), možno obrniti v lestvico sym naravnosti (in obratno, vsako lestvico, ki je utemeljena s stališča sym naravnosti (= poslušalca) je možno obrniti v lestvico sem naravnosti), zato se navedeno načelo za določanje sym naravnosti uporablja razmeroma redko.

\section{Nedoločniški polstavki s stališča teorije naravnosti}

S stališča teorije naravnosti so pasivni nedoločniški polstavki manj (sem) naravni od aktivnih nedoločniških polstavkov. Velja tudi, da je katerikoli, tudi določni stavek (t.j. stavek $z$ določno ali osebno glagolsko obliko) bolj sem naraven od aktivnega stavka. V obliki lestvice naravnosti se ta trditev izrazi kot:

$>\operatorname{sem}(\mathrm{A}, \mathrm{P}) /$ nedoločniški polstavek oz.

$>$ sem $(\mathrm{A}, \mathrm{P}) /$ stavek

Lestvico je možno utemeljiti s pomočjo več načel za določanje sem naravnosti. $V$ tem primeru navajam vsa načela, po katerih jo je možno utemeljiti, čeprav načeloma velja, da je lestvica naravnosti zadostno utemeljena že na podlagi enega od navedenih načel. Načela, po katerih je možno utemeljiti navedeni lestvici, so naslednja:

- tipološko načelo; Gotovo je aktiv v različnih jezikih sveta bolj razširjen kot pasiv. Že slovenščina predstavlja primer jezika, kjer je aktiv precej bolj pogost kot pasiv. Obratna lestvica naravnosti, po kateri bi bil aktiv manj naraven od pasiva, bi veljala samo v primeru, da bi obstajal jezik, ki ne bi poznal aktiva, temveč samo pasiv.

- načelo manjšega napora; Temeljna razlika med aktivnim in pasivnim nedoločniškim polstavkom je $\mathrm{v}$ tem, da se $\mathrm{v}$ prvem nujno rabi aktivni, $\mathrm{v}$ drugem pa pasivni nedoločnik. Tako $v$ aktivnem kot $v$ pasivnem nedoločniškem polstavku, ki je odvisen od enega od glagolov ukazovanja, je za tvorbo nedoločniškega polstavka poleg nedoločnika potreben samo

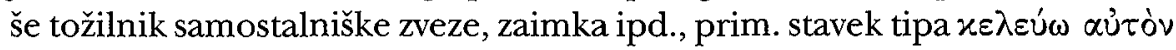

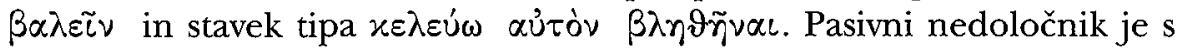


stališča načela manjšega napora manj naraven od aktivnega nedoločnik. O tem priča tudi grško oblikoslovje, kjer je očitna težnja po tem, da je pasivni nedoločnik daljši in s tem za govorca težji od aktivnega, prim.

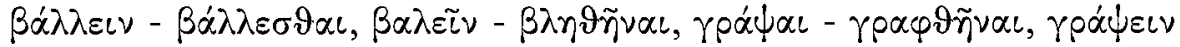
- $\gamma \rho \alpha \varphi \vartheta \dot{n} \sigma \varepsilon \sigma \vartheta \alpha \iota$.

- načelo transparentnosti; o tem prim. sp., str. 65

Nedoločniške polstavke je možno umestiti tudi v naslednjo lestvico naravnosti, ki bo uporabljena $\vee$ zaključku prispevka. Dvojnico tako predstavljajo tudi nedoločniški polstavki in predmetni odvisniki, ki jih $\mathrm{v}$ grščini uvajata veznika ơ $\tau$ oz. " ¿va. ${ }^{3}$ Slednji, to je predmetni odvisniki, uvedeni z veznikom " $v \alpha$, so postajali vse pogostejši v poklasični grščini in kasneje, ko so nedoločniške polstavke v celoti izpodrinili. Kot se domneva, naj bi nedoločnik iz govorjene grščine izginil do 10. st. po Kr., po drugih domnevah pa naj bi se nekatere nedoločnik v vsaj nekaterih osamljenih skladenjskih vlogah ohranil še skozi vso srednjeveško grščino. ${ }^{4}$

Pomenska sorodnost nedoločniških polstavkov in predmetnih odvisnikov, ki je eden od pogojev, da skladenjski dopolnili znotraj teorije naravnosti veljata za dvojnici, je v grščini zelo očitna v anakolutičnih stavkih, kjer je v nedoločniškem polstavku rabljen veznik, ki sicer uvaja predmetni odvisnik. Takšni primeri so izpričani v klasični dobi, prim. Kühner-Gerth

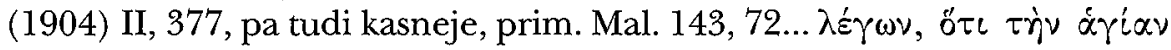

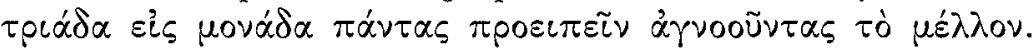

S stališča teorije naravnosti so nedoločniški polstavki bolj sem naravni od predmetnih odvisnikov, kar se v obliki lestvice izrazi kot:

$>$ sem (nedoločniški polstavek, predmetni odvisnik)

Lestvico je možno utemeljiti po naslednjih načelih:

- po načelu manjšega napora- Za tvorbo predmetnega odvisnika sta potrebni najmanj dve besedi (veznik in glagolska oblika), za tvorbo nedoločniškega polstavka pa najmanj ena (nedoločnik), tako da so nedoločniški polstavki (v povprečju) krajši in zato za govorca lažji od predmetnih odvisnikov.

- po načelu včlenjenosti v stavek- iz skladnje grškega nedoločnika je znano, da se nikalnica izpostavlja iz nedoločniških polstavkov, prim. Oủx

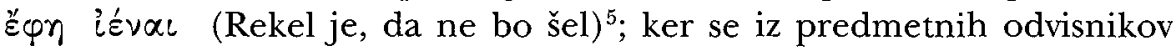
nikalnica ne izpostavlja, je to znamenje, da so nedoločniški polstavki bolj včlenjeni v stavek kot predmetni odvisniki. Drug primer bi bil, da se v nedoločniških polstavkih uporabljajo (tako kot v samostojnih stavkih)

3 Veznik íva je v tej skladenjski vlogi nadomestil starejši veznik ö $\pi \omega_{5}$. O tem, kateri glagoli so se že v klasični grščini dopolnjevali s predmetnimi odvisniki na -ót $\pi \omega$, prim. Kühner-Gerth (1904), II, 376.

4 Prim. Joseph (1983), 81, Horrocks (1997), 228.

5 Babič (1997), 110. 
povratni zaimki (indirektni refleksiv), medtem ko se $\mathrm{v}$ predmetnih odvisnikih indirektni refleksiv ne uporablja. To velja samo za skladnjo predmetnik odvisnikov in nedoločniških polstavkov v poklasični grščini, medtem ko klasična grščina je poznala indirektni refleksiv tudi v predmetnih odvisnikih, prim. Babič (1997), 77.

- po tipološkem načelu -Zgolj s stališča modernih evropskih jezikov nedoločniški polstavki niso bolj pogosti kot predmetni odvisniki, o čemer najbolje priča moderna grščina, ki nedoločnika nima. To je tudi eden od razlogov, zaradi katerih so bili v ti. celovški raziskavi o rabi nedoločnika $\mathrm{v}$ modernih evropskih jezikih nedoločniški polstavki opredeljeni kot manj naravni od predmetnih odvisnikov. Vendar je pri tipološkem načelu treba izhajati iz širšega stanja v svetovnih jezikih, še zlasti zato, ker večina modernih evropskih jezikov spada $v$ isto jezikovno družino, se pravi med indoevropske jezike. Po drugi strani obstajajo podatki, da nekateri jeziki tvorijo stavke samo s pomočjo brezosebnih oblik, in odvisnikov ne poznajo. Tako Aalto (1953), 97 kot primere jezikov, ki ne poznajo odvisnikov, tvorjenih s pomočjo osebnih glagolskih oblik, navaja mongolske in tibetanske jezike.

Že omenjeno raziskavo o skladnji nedoločnika v modernih evropskih jezikih je v opravila skupina jezikoslovcev iz Univerze v Celovcu. Njeni rezultati so bili objavljeni v dveh knjigah, prva (Mayethaler I) obravnava zahodnoevropske jezike in narečja, druga (Mayerthaler II) pa območje Alpe-Adrija (knjižno slovenščino ter nekatera slovenska narečja, knjižno hrvaščino, knjižno nemščino, bavarščino in tirolščino). Raziskava je nastala v okviru teorije naravnosti, in tako Mayerthaler I, 145, predlaga lestvico naravnosti nedoločniških polstavkov in predmetnih odvisnikov, po kateri so nedoločniški polstavki manj naravni od predmetnih odvisnikov. Lestvica je torej obratna od te, ki izhaja iz načel, ki jih za določanje naravnosti uporablja slovenska šola. Mayerthaler I, loc. cit., se sklicuje na dejstvo, da so osebne glagolske oblike bolj naravne od neosebnih.

$\mathrm{K}$ temu je možno pripomniti, da predmetni odvisniki in nedoločniški polstavki niso istovetni $z$ osebnimi oz. neosebnimi glagolskimi oblikami. Čeprav so na oblikoslovni ravni osebne glagolske oblike bolj naravne od neosebnih, je v skladnji za govorca lažje (kot izhaja iz zgoraj navedenih načel) uporabljati (pol)stavke, ki se tvorijo iz neosebnih glagolskih oblik (če te v jeziku obstajajo), ker neosebne glagolske oblike, kot kaže primer nedoločniških polstavkov in predmetnih odvisnikov, prispevajo $h$ varčnosti izražanja. Čeprav je glagolska oblika sama (v tem primeru nedoločnik) manj naravna (od osebne glagolske oblike v predmetnem odvisniku), je celotna konstrukcija, ki jo sestavlja neosebna glagolska oblika, bolj naravna od konstrukcije, ki je sestavljena iz osebne glagolske oblike, ker za govorca predstavlja manjši napor. Da raba nedoločniških polstavkov prispeva $\mathrm{k}$ 
varčnosti izražanja, ugotavlja tudi Mayerthaler I, 153: »Infinitivbildungen dienen vor allem der Kodierungsökonomie. Sie führen zur Reduktion der Anzahl lexikalisierter Elemente in der Satzkonstruktion.«

\section{Pasivni nedoločniški polstavki za glagoli ukazovanja v grščini}

V nadaljevanju obravnavam skladnjo nedoločniških polstavkov za glagoli ukazovanja $v$ primerih, ko naslovnik ukaza ni znan. Kot je bilo omenjeno na začetku, se $\mathrm{v}$ poklasični grščini podobno kot $\mathrm{v}$ latinščini $\mathrm{v}$ stavkih tipa Caesar pontem fieri iussit $\mathrm{v}$ primeru neizreženega naslovnika začnejo pogosteje uporabljati pasivni nedoločniški polstavki. Ta vidik skladnje grškega nedoločnika je razložen tudi s stališča teorije naravnosti.

V klasični grščini je bil nedoločniški polstavek, odvisen od glagolov ukazovanja, v primeru, da je bil naslovnik izpuščen, praviloma aktiven,

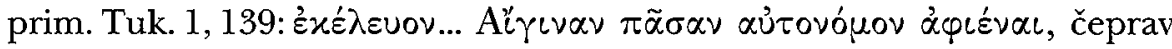
je tudi v klasični dobi izpričanih nekaj primerov, ko je nedoločniški polstavek pasiven, prim. Hult (1990), 153, ki navaja Ksenofonta, Hel. 1, 7,

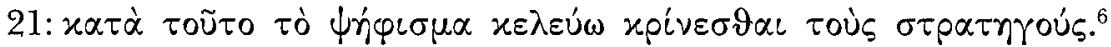

V poklasični grščini so se v primeru neizraženega naslovnika pogosteje

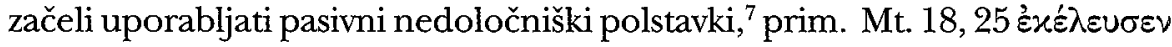

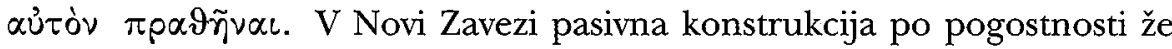
prevladuje nad aktivno. ${ }^{8}$ Pogostnost te konstrukcije na papirusnih najdbah ni znana, ker standardna slovnica neliterarnih papirusov iz Ptolemajskega obdobja (Mayser (1929)) konstrukcije ne obravnava posebej, prav tako ne Mandilaras (1973), ki obravnava oblikoslovje in skladnjo grškega glagola na vseh papirusnih najdbah do 8. st. po $\mathrm{Kr}$. Vendar so primeri gotovo izpričani tudi na papirusnih najdbah, ${ }^{9}$ kar potrjuje, da je bila konstrukcija v neliterarnih delih sprejemljiva.

Pasivni nedoločniški polstavki so natančneje raziskani v proznih delih 5. st. po Kr. v delu, ki ga je objavila Karin Hult (1990) in obravnava slog šestih proznih piscev tega obdobja. Namen raziskave je bilo določiti slogovno vrednosti izbranih skladenjskih dvojnic (kljub rabi izraza 'dvojnica', angl. 'variant' raziskava ni nastala v okviru teorije naravnosti). Rezultati so pokazali, da v proznih delih 5. st. po Kr. pasivni nedoločniški polstavek najpogosteje uporabljajo pisci, katerih slog je tudi sicer manj 'literaren' ('literary'), to so Paladij, Kalinik in Mark Diakon. Vendar pa ta

6 Vendar se ta konstrukcija v slovnicah klasične grščine praviloma ne omenja. Podatke za klasično dobo črpam iz Hult (1990), loc. cit.

7 Prim. zlasti Mihevc-Gabrovec (1972); drugi viri: BDR § 392, Hult (1990), $153 \mathrm{s.}$

8 Hult (1990), 155.

9 Prim. BDR, loc.cit., Mihevc-Gabrovec (1972), 91. 
tip nedoločniškega polstavka poznajo tudi pisci, ki na splošno pišejo bolj 'literaren' slog. ${ }^{10}$

Podobno stanje se nadaljuje kasneje, v 6. in v začetku 7. st. po Kr. Tako je v zgodnjesrednjeveških delih Pratum Spirituale, Kronika Janeza Malalasa in v Viti Teodorja iz Sikeona pogostnost pasivnih nedoločniških polstavkov v primeru izpuščenega naslovnika približno enaka kot prej, se pravi v proznih delih 5. st. po Kr. Prav tako pasivno konstrukcijo približno enako pogosto uporabljajo vsi trije navedeni avtorji, čeprav sta deli Pratum Spirituale in Kronika Janeza Malalasa v marsikatem pogledu slogovno bližje tedanjemu govorjenemu jeziku kot Vita Teodorja iz Sikeona. ${ }^{11}$

Kot rečeno, se pasivni nedoločniški polstavek v grščini praviloma uporablja tedaj, kadar naslovnik ni izražen, in v tem pogledu je konstrukcija podobna latinskim nedolčniškim polstavkom za glagoli ukazovanja. Zato bi bila možna razlaga, da gre za vpliv latinščine. ${ }^{12}$ Vprašanje latinskega vpliva je pomembno tudi s stališč teorije naravnosti, ki raziskuje jezikovne pojave, ki se $\mathrm{v}$ jeziku razvijejo spontano in ne pod zunanjim vplivom. Vendar med latinsko in grško konstrukcijo obstajajo tudi precejšnje razlike: tako se v grščini pasivni nedoločniški polstavek včasih uporablja tudi, kadar je naslovnik v stavku omenjen ali kadar je nanj možno sklepati iz sobesedila. ${ }^{13}$ Pasivni nedoločniški polstavek se lahko tudi znotraj istega stavka izmenjuje $z$ aktivnim. Poleg tega $v$ grščini pasivni nedoločniški polstavek tudi v primeru, ko naslovnik ni izražen, ni bil nikoli obvezen. Namesto pasivne konstrukcije se je lahko uporabljala tudi aktivna. ${ }^{14}$ Zaradi razlik med latinsko in grško skladnjo je torej manj verjetno, da bi na razvoj grške konstrukcije vplivala latinščina, poleg tega pa se je konstrukcija v grščini pojavila že v času, ko latinščina nanjo še ni mogla vplivati, saj je nekaj primerov izpričanih že v klasični dobi. ${ }^{15}$

O naravnosti aktivnih in pasivnih nedoločniških polstavkov je bilo govora že zgoraj. Na tem mestu dodajam, da se v virih, ki obravnavajo pasivne nedoločniške polstavke $v$ poklasični grščini, $v$ zvezi $z$ njimi zelo pogosto uporablja izraz 'transparentnost', prim. Hult (1990), 155: 'It may indeed be regarded as more transparent than the simple infinitive since there is no doubt that the accusative refers to the object of the action denoted by the infintive; with the active infinitive the accusative may be

${ }^{10}$ Hult (1990), 170.

${ }^{11}$ Prim. Kavčič (2003), 138, 9.

12 Prim. Mihevc-Gabrovec, op. cit., 95.

${ }^{13}$ Prim. Ljungvik (1926), 43; Mihevc-Gabrovec, op. cit., 95.

${ }^{14}$ Prim. Ljungvik (1926), loc. cit.

${ }^{15}$ Prim. Mihevc-Gabrovec, op. cit, 96 . Hultova (1990), loc. cit., po drugi strani dopušča možnost, da je imela latinščina vpliv vsaj na pogostnost pasivnih nedoločniških stavkov pri nekaterih piscih. 
ambigous." ${ }^{16}$ Pojem transparentnosti pa je glavni kriterij pri določanju sym naravnosti. Tako je lestvica naravnosti >sem (aktivni, pasivni)/ nedoločniški polstavki utemeljena tudi s stališča sym naravnosti.

Poseben primer, ki je poseben tudi s stališča teorije naravnosti, predstavljajo stavki, kjer je rabljen pasivni nedoločnik kljub temu, da je naslovnik ne le znan, ampak tudi izražen. Takšni stavki se navajajo, čeprav redko, prim. Ljungvik (1926), 43, ki citira naslednji stavek: Pass. Barth.

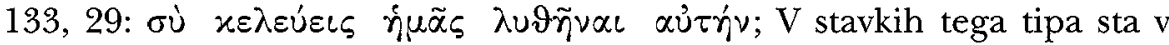
nedoločniškem polstavku navedeni dve osebi, in ni jasno, katera je naslovnik in katera predmet dejanja nedoločniškega polstavka, tako da pasivni stavek ni nič bolj transparenten od aktivnega.

Pasivni nedoločniški polstavki, rabljeni v primeru neizraženega naslovnika, so lahko zanimivi tudi $z$ naslednjega vidika: $v$ grščini so se pasivni nedoločniški polstavki v primeru neizraženega naslovnika začeli uporabljati v času, ko je nedoločnik večino skladenjskih vlog, v katerih se je uporabljal v klasični grščini, izgubljal ali jih že v celoti izgubil. Tako je bil ob koncu antike (5., 6. st. po Kr.) nedoločnik zelo redek ne le kot dopolnilo glagolov govorjenja in mišljenja ( $\mathrm{v}$ tej skladenjskih vlogi so ga že v klasični dobi deloma lahko nadomeščali predmetni odvisniki), ampak tudi kot dopolnilo glagolov ukazovanja in celo kot dopolnilo modalnih glagolov ('moči, morati, hoteti'). Edini modalni glagol, kjer v tem času predmetni odvisniki še niso izpričani, je glagoli 'moči' $(\delta u ́ v \alpha \mu \alpha \iota) .{ }^{17}$ Domneva se celo, da se prva znamenja, ki kažejo na izginjanje nedoločnika iz govorjenega jezika, kažejo že ob koncu klasične dobe. ${ }^{18}$ Kljub temu so se ravno v poklasični dobi začeli širiti pasivni nedoločniški polstavki, ki so bili v klasični dobi zelo redki in za grščino neznačilni. Vpliv latinščine bi bil v tem primeru preprosta rešitev, proti kateri pa govorijo ne le razlike med latinsko in grško konstrukcijo, ampak tudi to, da so v grščini še ob koncu antike pasivni nedoločniški polstavki povsem običajni v delih, ki pisana pod sorazmerno velikim vplivom tedanjega govorjenega jezika. Tudi to vprašanje je možno obravnavati s stališča teorije naravnosti, o čemer prim. sp.

\section{Raba pasivnih nedoločniških polstavkov s stališča teorije naravnosti}

Teorija naravnosti lahko razloži naslednje vidike skladnje pasivnih nedoločniških polstavkov, ki so odvisni od glagolov ukazovanja:

\footnotetext{
${ }^{16}$ Prim. tudi Wolf (1912) II, 68: »Der Deutlichkeit dient gleichfalls die bei Malalas sehr beliebte Verwendung des passiven statt des aktiven Infinitivs. «

${ }_{17}$ Prim. Kavčič (2003), 164, 187.

${ }^{18}$ Prim. Joseph (1983), 49.
} 
-Zakaj so ravno pasivni nedoločniški polstavki bolj transparentni od aktivnih. Teorija naravnosti trdi, da je nujno tako in da ni možno, da bi bili v katerikoli dvojnici aktivni/pasivni stavek aktivni stavek bolj transparenten od pasimnega, seveda v primeru, da obstaja razlika $\mathrm{v}$ transparentnosti obeh stavkov.

-Glagoli, ki povzročajo netransparentnost v nedoločniških polstavkov, so prehodni glagoli, in to zlasti direktno prehodni glagoli (prim. sp.). Teorija naravnosti lahko utemelji, zakaj lahko takšne nejasnosti povzroča samo manj naravna skupina glagolov in zakaj je prehodni glagoli možno opredeliti kot manj naravne od nepredhodnih.

- Kar se tiče stavkov rabe pasivnih nedoločniških polstavkov v primerih, ko je naslovnik v stavku izražen, premislek pokaže, da so stavki tega tipa povsem v skladu s teorijo naravnosti in da je s stališča te teorije celo bolj pričakovano, da se stavki tega tipa uporabljajo kot pa da se ne uporabljajo.

- Glede rabe pasivnih nedoločniških polstavkov v času, ko naj bi nedoločnik iz grščine že izginjal in v nekaterih skladenjskih vlogah, znanih iz klasične grščine, tudi že izginil, je s stališča teorije naravnosti možno razložiti, zakaj je povsem mogoče, da so se stavki tega tipa v poklasični grščini razvili spontano in da pri razlagi njihovega nastanka ni treba predpostavljati tujega (latinskega) vpliva.

I. Kot rečeno, je v primeru, ko je naslovnik izpuščen, aktivni nedoločniški polstavek manj transparenten od pasivnega. Natančneje povedano, v primeru aktivne konstrukcije ni jasno, ali je tožilnik v nedoločniškem polstavku vršilec dejanja, ali predmet, na katerem se mora dejanje izvršiti. Če je nedoločniški polstavek v pasivu, se to ne zgodi, ker je jasno, da je osebek nedoločniškega polstavka, izražen v tožilniku, predmet, na katerem so mora dejanje izvršiti, in da je nekdo drug vršilec

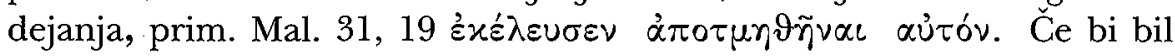

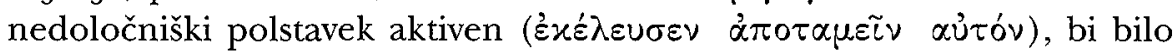
tožilnik aủ óv možno razumeti tudi kot vršilca dejanja.

S stališča teorije naravnosti je možno razložiti, zakaj ni mogoče, da bi bil aktivni nedoločniški polstavek bolj transparenten od pasivnega. Transparentnost skladnje je namreč v interesu poslušalca, interes poslušalca pa se lahko uveljavi v manj sem naravnih okoliščinah, kar je v danem primeru pasiv, ki je manj sem naravna kategorija od aktiva.

dvojnici: aktivni nedoločniški polstavek za glagoli ukazovanja $z$ neizraženim naslovnikom, pasivni nedoločniški polstavek za glagoli ukazovanja $\mathrm{z}$ neizraženim naslovnikom

\section{1. lestvice naravnosti:}

1.1 >sym $(+,-) /$ transparentnost vršilca dejanja in predmeta

- po načelu transparentnosti

1.2. >sem (aktivni, pasivni)/nedoločniški polstavek 
-po načelu manjšega napora, prim. zg.

- po tipološkem načelu, prim. zg.

2. pravila vzporejanja:

2. 1. $>$ sym se povezuje $\mathrm{s}<$ sem

2. 2. $<$ sem se povezuje $s<$ sem

3. napoved: C̆e je kaka razlika med aktivnimi in pasivnimi nedoločniškimi polstavki za glagoli ukazovanja z neizraženim naslovnikom $\mathrm{v}$ tem pogledu, da sta $\mathrm{v}$ enem primeru vršilec dejanja in predmet bolj transparentna kot v drugem primeru, potem sta $v$ pasivnih nedoločniških polstavkih vršilec dejanja in predmet bolj transparentna kot $\mathrm{v}$ aktivnih nedoločniških polstavkih $\mathrm{z}$ izpuščenim naslovnikom.

II. Nejasnosti glede vršilca dejanja nastanejo samo tedaj, kadar je glagol, uporabljen v nedoločniškem polstavku, (direktno) prehoden. ${ }^{19} \mathrm{~V}$ pasivnih nedoločniških polstavkih $\mathrm{z}$ izpuščenim naslovnikom je glagol vedno (direktno) prehoden, medtem ko je $\mathrm{v}$ aktivnih nedoločniških polstavkih $\mathrm{z}$ neizraženim naslovnikom glagol lahko (direktno) prehoden ali neprehoden; kot primer (direktno) prehodnega glagola $\mathrm{v}$ aktivnem nedoločniškem

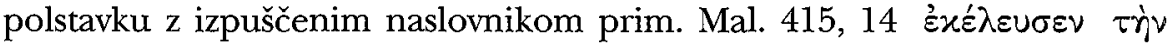

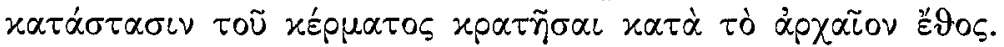

Po teoriji naravnosti bi bili prehodni glagoli manj naravni od neprehodnih, kar je možno utemeljevati po načelu pogostnosti. Nekateri najbolj pogosti glagoli v jeziku, na primer glagol biti ali glagol 'moči', so namreč po pomenu stanjski in so neprehodni.

dvojnici: aktivni nedoločniški polstavek $\mathrm{z}$ neizraženim naslovnikom, pasivni nedoločniški polstavek $z$ neizraženim naslovnikom

\section{1. lestvice naravnosti:}

1.1. >sem (aktivni, pasivni)/nedoločniški polstavki z neizraženim naslovnikom

-prim. zg.

2. 1. >sem (neprehodni, prehodni)/glagoli

- po načelu manjšega napora, prim. zg.

- po načelu pogostnosti, prim. zg.

1.2. 1. >sem (neprehodni +prehodni, prehodni)/glagoli -lestvica tipa $>\operatorname{sem}(A, B) \rightarrow>\operatorname{sem}(A+B, B)$, prim. $z$ g.

\section{2. pravila vzporejanja:}

2. 1. $>$ sem se povezuje $s>$ sem

2. 2. <sem se povezuje $s<$ sem

${ }^{19}$ Vsaj v obravnavanih delih indirektno prehodni glagloli v nedoločniških polstavkih $z$ izpuščenim naslovnikom niso izpričani. Tudi indirektno prehodni glagoli so sicer v grščini lahko tvorili pasiv, prim. Babič (1997), 96. 
3. napoved: Če obstaja razlika med aktivnimi in pasivnimi nedoločniškimi polstavki z neizraženim naslovnikom, tako da se $\mathrm{v}$ enih uporabljajo samo neprehodni glagoli, $v$ drugih pa se uporabljajo neprehodni ali prehodni glagoli, potem se $\mathrm{v}$ aktivnih nedoločniških polstavkih $\mathrm{z}$ neizraženim naslovnikom uporabljajo neprehodni ali prehodni glagoli, $\mathrm{v}$ pasivnih nedoločniških polstavkih $\mathrm{z}$ neizraženim naslovnikom pa se uporabljajo samo prehodni glagoli.

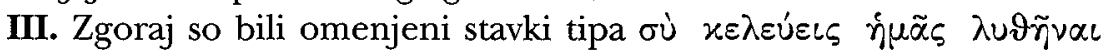
aủińv, kjer je pasivni nedoločnik rabljen kljub temu, da je naslornik ne le poznan, ampak v nedoločniškem stavku tudi izražen. Kot rečeno, v tem primeru pasivna konstrukcija ni bolj transparentna od aktivne, kar bi lahko predstavljalo težavo za teorijo naravnosti. Vendar obstoj takšnih stavkov ni v nasprotju s teorijo naravnosti, in sicer iz naslednji razlogov.

1. Stanje, ki bi bilo v neskladju $z$ napovedmi teorije naravnosti bi nastopilo, ko bi bili pasivni nedoločniški polstavki z izraženim naslovnikom manj transparentni (glede vršilca dejanja) od njihovih dvojnic v aktivu, kker je pasivni nedoločniški polstavek manj sem naraven od aktivnega, od manj sem naravne kategorije pa se pričakuje večja transparentnost kot od bolj sem naravne kategorije. Pasivni nedoločniški polstavki z izraženim naslovnikom niso manj transparentni (kar se tiče vršilca dejanja) od njihovih aktivnih dvojnic, temveč sta obe dvojnici v tem pogledu enako (ne) transparentni; to, da se dvojnici $v$ transparentnosti (glede vršilca dejanja) ne razlikujeta, ni v neskladju s teorijo naravnosti, ker ta ne napoveduje, da se morata dvojnici $\mathrm{v}$ nekem določenem pogledu nujno razlikovati. Teorija naravnosti podaja napovedi samo v primeru, ko je znano, da med obema dvojnicama obstaja razlika v določenem pogledu.

2. Možno je zagovarjati stališče, da je stanje, ko v jeziku obstajajo poleg pasivnih nedoločniških polstavkov $z$ izraženim naslovnim tudi pasivni nedoločniški polstavki $\mathrm{z}$ neizraženim naslovnikom, bolj $\mathrm{v}$ pričakovano, kot če pasivnih nedoločniških polstavkov $z$ neizraženim naslovnikom ne bi bilo. Po teoriji naravnosti so namreč nedoločniški polstavki z neizraženim naslovnikom bolj sem naravni od nedoločniških polstavkov $z$ izraženim naslovnikom (lestvica >sem (neizražen naslovnik, izražen naslovnik), se utemelji po načelu manjšega napora). Če bi bil torej v primeru izraženega naslovnika možen samo aktiven nedoločniški polstavek, $\mathrm{v}$ primeru neizraženega naslovnika pa aktiven in pasiven nedoločniški polstavek, bi bilo takšno stanje $\mathrm{v}$ neskladju $\mathrm{z}$ napovedmi teorije naravnosti. Napoved teorije naravnosti bi namreč bila, da če obstaja razlika med nedoločniškimi polstavki z izraženim naslovnikom in med nedoločniškimi polstavki z neizraženim naslovnikom, tako da je v enem primeru možna samo aktivna konstrukcija, v drugem primeru pa je možna aktivna ali pasivna konstrukcija, potem je $v$ nedoločniških polstavkih $z$ neizraženim naslovnikom možna 
samo aktivna konstrukcija, v nedoločniških polstavkih $z$ izraženim naslovnikom pa sta možni aktivna in pasivna konstrukcija. Obstoj samo aktivne konstrukcije je namreč bolj sem naraven kot obstoj aktivne in pasivne konstrukcije, in bolj sem naravne skladenjske lastnosti se uveljavljajo v prav tako sem naravnih okoliščinah ( $v$ danem primeru je to odsotnost naslovnika v nedoločniškem polstavku). Stanje v grščini pa ni takšno, ker so pasivni nedoločniški polstavki zelo pogosto izpričani prav v primeru neizraženega naslovnika. Ker sta dejansko možni tako aktivna kot pasivna konstrukcija bodisi če je naslovnik izražen bodisi če ni izražen, takšno stanje ni v neskladju s teorijo naravnosti.

IV. Kot rečeno, so se pasivni nedoločniški polstavki $\mathrm{v}$ primeru neizraženega naslovnika v grščini začeli pogosteje uporabljati šele v času, ko se predvideva, da je nedoločnik iz govorjenega jezika že izginjal. S stališča teorije naravnosti bi bilo možno povedati naslednje: gledano zgolj s sihronega vidika, ki je teoriji najbolj lasten, ni raba pasivnih nedoločniških stavkov v nobenem obdobju v grščini v neskladju pričakovanji teorije naravnosti. Tako stanje bi denimo nastopilo, če bi se za glagoli ukazovanja v nekem obdobju uporabljali samo pasivni nedoločniški polstavki, medtem ko bi se v manj naravnih skladenjskih razmerah, na primer za glagoli govorjenja in mišljenja, uporabljali samo aktivni nedoločniški polstavki. ${ }^{20}$ Takšne razmere pa se v grščini nikoli niso uresničile. Če se na nastanek pasivnih nedoločniških polstavkov za glagoli ukazovanja gleda tudi $z$ zgodovinskega vidika (kljub temu, da se ta vidik v novejših različicah teorije naravnosti vse bolj opušča), je možno ugotoviti naslednje: težnja po rabi pasivnih nedoločniških polstavkov v primeru neizraženega naslovnika je težnja po večji sym naravnosti (manjši sem naravnosti) skladnje nedoločniških polstavkov, ker so pasivni stavki manj sem naravni od aktivnih. Teorija naravnosti sicer ne more razložiti, zakaj se ta težnja v nekem trenutku uveljavi, vendar pa je tudi v nekaterih drugih novostih v skladnji nedoločniških polstavkov v poklasični dobi možno videti isto težnjo. To velja že za spremembo, ki je slednjič zajela prav vse skladenjske vloge nedoločnika, namreč za to, da so nedoločnik v celoti nadomestili predmetni odvisniki. Predmetni odvisniki pa v dvojnici z nedoločniškimi polstavki predstavljajo manj naravno skladenjsko možnost (za utemeljitev prim. zg., str. 63).

Teorija naravnosti torej ne more razložiti, zakaj se je ta težnja ravno v grščini izpeljala do konca, vendar pa je z njeno pomočjo možno osmisliti nekatere druge skladenjske spremembe $v$ poklasični grščini, med katere sodi raba pasivnih nedoločniških polstavkov v primeru neizraženega naslovnika.

${ }^{20}$ Za utemeljitev, zakaj so glagoli govorjenja in mišljenja s stališča skladnje nedoločnika manj naravne razmere od glagolov ukazovanja prim. Orešnik (1999), 56, Mayerthaler I, 150 . 


\section{BIBLIOGRAFIJA}

AALTO (1953): Studien zur Geschichte des Infinitivs in Griechischen, Helsinki

BDR: Blass/Debrunner/Rehkopf $\left(1975^{14}\right)$ : Grammatik des neutestamentlichen Griechisch, Göttingen

BABIČ (1997): Grška slovnica, Ljubljana

HULT (1990): Syntactic variation in Greek of the 5th century AD, Göteborg HORROCKS (1997): Greek, A history of the language and its speakers, London and New York

JOSEPH (1983): The synchrony and diachrony of the Balkan infinitive, Cambridge

KAVČIČ (2003): Skladenjske in slogovne značilnosti neosebnih glagolskih oblik v grški prozi zgodnjega srednjega veka, Ljubljana (doktorska disertacija)

KOPRIVA (1976): Latinska slovnica, Ljubljana

KÜHNER-GERTH (1904): Ausführliche Grammatik der griechischen Sprache I-II, Hannover und Leipzig

LJUNGVIK (1926): Studien zur Syntax der spätgriechischen Volksprache, Uppsala

MAYERTHALER (I): Willi Mayerthaler/Günther Fliedl/Christian Winkler: Infinitivprominenz in europäischen Sprachen, Teil I: Die Romania (samt Baskisch), Tübingen 1993

MAYERTHALER (II): Willi Mayerthaler/Günther Fliedl/Christian Winkler: Infinitivprominenz in europäischen Sprachen, Teil II: Der Alpen-Adria Raum als Schnittstelle von Griechisch, Romanisch und Slawisch, Tübingen 1995

MALALAS (Thurn 2000): Chronographia Ioannis Malalae, New York and Berlin

MANDILARAS (1973): The verb in Greek non-literary papyri, Athens

MAYSER (1936): Grammatik der griechischen papyri aus der Ptolemäerzeit I-II, Berlin und Leipzig

MIHEVC-GABROVEC (1972): L' infinitif du passif avec les verba iubendi, v: Živa antika XXII, 91-97

OREŠNIK (1999): Krepke in šibke dvojnice v skladnji, Ljubljana

OREŠNIK (2001): A predictable aspect of (morpho)syntactic variants, Ljubljana

ORESTNIK (2001): Naturalness expressed in sem-values, Ljubljana

OREŠNIK (2004): Naturalness in (morpho) syntax, Ljubljana WOLF (1912): Studien zur Sprache des Malalas I-II, München 
Passive Infinitive Clauses Dependent on the Verbs of Ordering: A View from the Naturalness Theory Perspective Summary

The passive infinitive clause used after a verb of ordering, with the addressee left unexpressed, was a rather uncommon structure in Classical Greek. Its use increased in the Post-Classical period, and was still frequent in Early Byzantine Greek. In terms of the Naturalness Theory (NT), the passive infinitive clause is interpreted as the less sem natural variant than the active. In the pair of variants infinitive clause / finite object clause, on the other hand, the infinitive clause is the more sem natural variant. The NT can thus explain why it is the passive and not the active infinitive clause that makes the clause structure more transparent, and why it is likely that the increased use of the passive infinitive clause was a development internal to Post-Classical Greek.

Naslov:

dr. Jerneja Kavčič

Univerza v Ljubljani, Filozofska fakulteta

Aškerčeva 2

SI-1000 Ljubljana

e-mail: jernejakavcic@hotmail.com 